\title{
Special Issue on Corrosion-Mechanical Loading Interactions
}

\author{
Y. Wouters ${ }^{1}$ (D) B. Pint ${ }^{2} \cdot$ D. Monceau ${ }^{3}$
}

Received: 8 February 2017/ Published online: 4 March 2017

(C) Springer Science+Business Media New York 2017

In the field of high-temperature oxidation, there are a wide number of problems are linked to the mechanical breakdown of the oxide scale. This can result in the observation of spallation, delamination, formation of microcracks, intergranular oxidation, etc. Sources of stress are numerous and most often associated with scale growth, variations of temperature or mechanical loading. Corrosion-mechanical loading interactions are relevant to all material systems that rely on scale formation for protection and therefore include basic carbon steels through to higher alloyed systems like superalloys.

A challenge is to experimentally simulate in-service conditions. This challenge increases when attempting to couple loading conditions with the environmental exposure conditions. Often, loading is applied via tensile and/or deflection tests, sometimes at high temperature under oxidizing conditions and coupled to a CCD camera or an SEM. Others techniques like synchrotron radiation may also be used. Experimental observations can be confronted with analytical approaches in order to assess key data (for example adhesion energy) and should take into account critical parameters like creep, relaxation, and the role of porosity in order to predict stress evolution with oxidation time, crack propagation rate and more generally, the actual service life of a given component.

\section{Y. Wouters}

yves.wouters@univ-grenoble-alpes.fr

B. Pint

pintba@ornl.gov

D. Monceau

daniel.monceau@ensiacet.fr

1 SIMaP, Université Grenoble Alpes, Grenoble, France

2 Materials Science and Technology Division, Oak Ridge National Laboratory, Oak Ridge, TN 37831-6156, USA

3 INP Toulouse-CNRS CIRIMAT, 31030 Toulouse, France 
The following key papers stem from presentations that were given at the 9 th international conference on High Temperature Corrosion and Protection of Materials (HTCPM2016), which was held at Les Embiez Island, France, on the May 15-20, 2016. 